OPEN

SUBJECT AREAS:

VOLCANOLOGY

GEOLOGY

Received

8 July 2013

Accepted

15 October 2013

Published

30 October 2013

Correspondence and requests for materials should be addressed to G.C. Igilda.currenti@ ct.ingv.it)

\section{Capturing the fingerprint of Etna volcano activity in gravity and satellite radar data}

\author{
Ciro Del Negro', Gilda Currenti' , Giuseppe Solaro², Filippo Greco', Antonio Pepe², Rosalba Napoli', \\ Susi Pepe ${ }^{2}$, Francesco Casu² \& Eugenio Sansosti ${ }^{2}$
}

\author{
${ }^{1}$ Istituto Nazionale di Geofisica e Vulcanologia, Sezione di Catania, Osservatorio Etneo, Italy, ${ }^{2}$ Istituto per il Rilevamento \\ Elettromagnetico dell'Ambiente, CNR, Napoli, Italy.
}

Long-term and high temporal resolution gravity and deformation data move us toward a better understanding of the behavior of Mt Etna during the June 1995 - December 2011 period in which the volcano exhibited magma charging phases, flank eruptions and summit crater activity. Monthly repeated gravity measurements were coupled with deformation time series using the Differential Synthetic Aperture Radar Interferometry (DInSAR) technique on two sequences of interferograms from ERS/ENVISAT and COSMO-SkyMed satellites. Combining spatiotemporal gravity and DInSAR observations provides the signature of three underlying processes at Etna: (i) magma accumulation in intermediate storage zones, (ii) magmatic intrusions at shallow depth in the South Rift area, and (iii) the seaward sliding of the volcano's eastern flank. Here we demonstrate the strength of the complementary gravity and DInSAR analysis in discerning among different processes and, thus, in detecting deep magma uprising in months to years before the onset of a new Etna eruption.

\footnotetext{
R
} epeated gravity surveys and ground deformation measurements have become effective volcano monitoring tools for mid- to long-term hazard assessment, by providing unique insights into processes that involve mass redistribution and/or pressure changes within volcano edifices ${ }^{1,2}$. Modeling of deformation sources by using ground deformation data alone usually suffers from the inability of resolving mass and density variations in the subsurface. The combined analysis of time-dependent gravity and surface deformation data can effectively constrain the mass of the source ${ }^{3,4}$. Depending on its physical properties, the arrival of fresh magma can cause a mass increase that may have little or no interaction with the surrounding medium. In this case, a limited ground deformation occurs, while a significant gravity increase is measurable at the surface $^{5}$, thus making the analysis of gravity time changes particularly relevant even when negligible ground deformation is observed ${ }^{6-8}$.

Time-dependent gravity and ground deformation measurements are, therefore, complementary to each other and their regular recording may disclose and clarify complex volcanic dynamics. An extraordinary gravity and ground deformation data set, in terms of continuity and duration, has been gathered at Etna since 1995. Monthly repeated gravity measurements have been carried out along a 24-kilometer West-East trending profile of 19 stations on the volcano's southern flank to monitor the dynamics of the main volcanic and tectonic features (Fig. 1). Earlier efforts at jointly detecting and interpreting deformation and gravity changes in a long-term perspective were hampered by the misplacement of gravity and GPS stations and by the lower temporal resolution of GPS data (yearly geodetic surveys).

The DInSAR measurements ${ }^{9,10}$ may overcome these issues allowing the detection of centimeter- to millimeterscale ground deformation at a high spatial and temporal resolution ${ }^{11}$. The availability of large SAR data archives, acquired from 1992 to 2010 by ERS/ENVISAT and since 2009 by COSMO-SkyMed satellites, enables us to recognize and measure the deformation evolution of significant portions of Etna volcano with a high density of measurements over nearly 2 decades ${ }^{12}$. Separate analysis of the DInSAR ${ }^{13}$ and gravity data ${ }^{14,15}$ have been recently performed, showing significant correlations between the eruptive and flank dynamics of Etna volcano and the spatiotemporal pattern changes of either DInSAR or gravity data.

We jointly analyze and compare, for the first time, all the available gravity and DInSAR datasets covering the 1995-2011 period in order to detect and interpret common patterns in their spatiotemporal evolution. This longterm and high temporal resolution dataset constitutes a unique opportunity to examine the behavior of Etna's southern flank in a period in which the volcano exhibited different styles of activity characterized by magma recharging, flank eruptions, and fountaining episodes. Here we demonstrate the strength of the complementary 


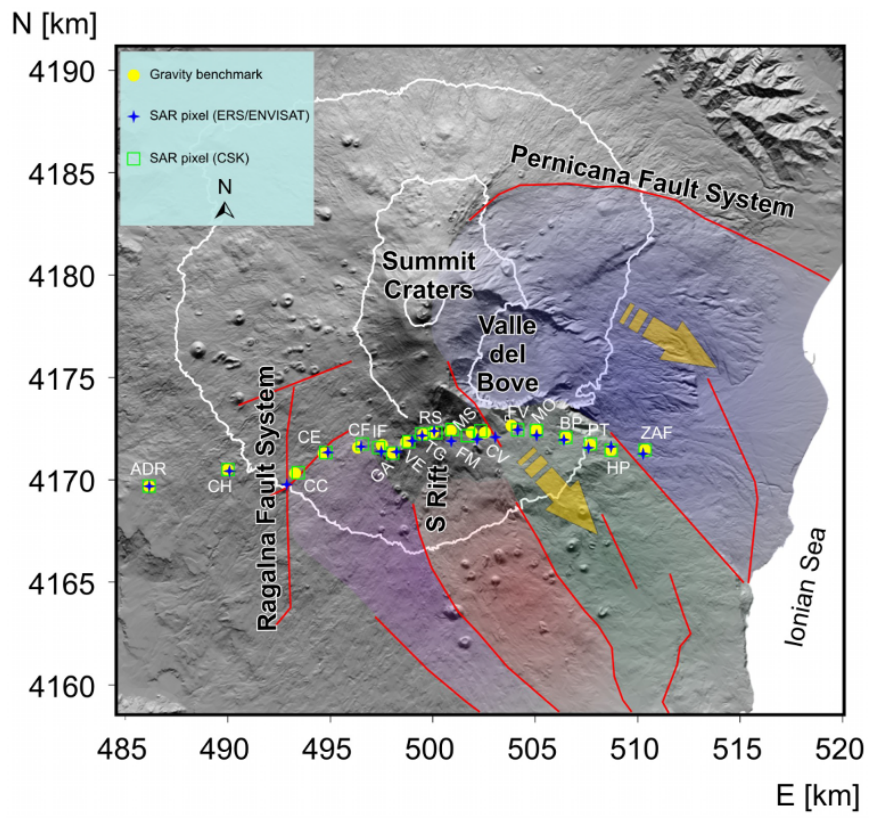

Figure $1 \mid$ Etna volcano map with the location of the gravity stations running from Adrano (ADR) to Zafferana (ZAF) villages across the Rifugio Sapienza (RS). The closest SAR pixels to the gravity stations are also reported for the ERS/ENVISAT and CSK time series. The major surface fault systems (red lines) border the main rigid blocks (colored shaded areas) of the eastern flank sliding ${ }^{21}$, which is delimited by the Ragalna fault to the SW and by the Pernicana fault to the NE. Geographical coordinates are expressed in UTM projection, zone 33N. All the figures in this paper were generated using a DEM owned by INGV.

gravity and DInSAR analysis in distinguishing the response of Etna volcano to different processes, posing the basis to track the unrest evolution and to forecast the style of future eruptions.

\section{Results}

Volcano-tectonic setting and recent eruptive activity. The gravity profile lies in a complex geodynamical context and intersects some of the main structural features of this Etna sector and areas undergoing different dynamical behaviors: the Ragalna fault System, the South Rift, and the eastern flank sliding sector (Fig. 1). The Ragalna fault System composed of a complex arrangement of at least three main faults dissecting the SW flank of the volcano, represents the southwestern boundary of the eastward moving sector ${ }^{16,17}$, separating a stable block on its western side from the mobile southern sector on its eastern side. The South Rift, radiating from the summit, is probably shallow rooted and has been usually laterally fed by the central conduit ${ }^{12}$ and exceptionally by the emplacement of peripheral vertically propagating deeper dikes ${ }^{18}$, as occurred during the 2001 and 2002-2003 flank eruptions. The eastern flank of the volcano shows a fairly continuous seaward motion, due to the interplay of gravity instability and magma intrusion ${ }^{19-21}$.

Between 1995 and 2011, Etna volcano exhibited different eruptive styles characterized by quasi-persistent activity from the summit craters and frequent lateral eruptions from vents situated on the volcano flanks. During the first six years (mid-1995 to mid-2001) the eruptive activity was confined to the summit area, where lava flows, lava fountains and powerful explosive events occurred in rapid succession at the summit craters (Fig. 1). Since 2000, Etna's activity moved toward more explosive styles ${ }^{22}$. The next four years were marked by two highly explosive and destructive flank eruptions in 2001 and 2002-2003, which coincided with a sharp drop in summit activity, and then by two dynamically singular, passive flank effusions in 2004-2005 and 2006. After the last effusive event occurred in
2008-2009, the volcano remained largely quiescent until 2011, when the Etna activity renewed with frequent, intermittent episodes of lava fountains from the South-East Crater (18 episodes in 2011).

Geophysical constraints on Etna dynamics. This intensive volcanic activity has been marked by significant spatiotemporal changes in DInSAR and gravity data ${ }^{12,15}$. A joint examination of the deformation and gravity maps (Figs. 2, 3 and Methods) highlights time intervals in which the analyzed signals underwent contemporaneous changes occurring mainly in the central and eastern stations of the profile, while lower amplitude changes are observed in the westernmost stations. From 1995 to 2001, a gravity variation cycle and an overall inflation of the volcano ${ }^{23,24}$, with horizontal expansion and diffuse uplift, are observed. This style was abruptly interrupted by the 2001 flank eruption and, after the 2002-2003 eruption, a new more complex behavior arose with predominantly negative gravity changes in the central and eastern portions of the profile, accompanied by discontinuous positive and negative increases in height changes and by outstanding horizontal deformation. This behavior stopped in 2009 when, new positive gravity changes were observed and the vertical deformation slowed down after about 8 years of continuous decrease.

The gravity-height changes, plotted in a $\Delta \mathrm{g} / \Delta \mathrm{h}$ diagram (Fig. 4 ), do not show any clear correlation, as usually expected in volcanic areas $^{5}$. The spatiotemporal gravity and DInSAR changes have varied substantially both in time and in space, and cannot be easily explained by a unique process affecting the whole profile. We can distinguish five main different patterns in the $\Delta \mathrm{g} / \Delta \mathrm{h}$ diagram at stations located in distinct sectors bounded by volcano-tectonic structures (Fig. 1). This could reflect the response of the volcano to different mechanisms. Indeed, in the region covered by the measurements, the dynamics of Etna volcano is generally controlled by three main processes ${ }^{12}$, which have been constrained by the gravity and DInSAR observations.

Magma accumulations in storage zones. The first process is related to the inflation of the volcano due to the accumulation of magma rising from depth, which induces positive gravity variations, moderate uplift and horizontal displacements of the volcano flanks. The long-term datasets point out at least three main magma charging phases. A first charging phase started during the late months of 1995, when a gravity increase/decrease cycle begun, which reached the maximum amplitude of about $50 \mu \mathrm{Gal}$ at the beginning of 1997 and ended in mid-1998 (Fig. 3c, box I). A second increase/decrease gravity cycle, affecting mostly the central and western portions of the profile, started at the mid-1999, culminating at the mid-2001 (maximum amplitude about $30 \mu \mathrm{Gal}$ ) and continuously decreasing until mid-2002 (Fig. 3c, box II). These two gravity cycles are accompanied by a moderate uplift of about $3 \mathrm{~cm}$ and a horizontal displacement of approximately $-3 \mathrm{~cm}$ and $6 \mathrm{~cm}$ in the western and eastern flanks, respectively. After 2001, the gravity increase/decrease cycles faded away accompanied with an overall negative trend in the vertical deformation (about $-1 \mathrm{~cm} /$ yr) until 2009. After about 8 years of absence of significant gravity cycles, a new marked and persistent increase in gravity changes started at the beginning of 2010 and continued during the last survey carried out in December 2011, when it reached a maximum amplitude of about $60 \mu \mathrm{Gal}$ (Fig. 3c, box III). The increase of gravity field recorded in this period is among the largest ever recorded along the profile. Contemporaneously, the negative trend in the vertical deformation came to an end (TG station in Fig. 2a). By comparing the long-term gravity increase/decrease cycles with a chronogram of the paroxysmal activity at the summit craters and the flank eruptions of Etna, a qualitative correspondence in time between positive gravity changes and intense eruptive activity is observed (Fig. 3).

Usually, gravity-height changes associated with recharging phases at many volcanoes have been found to follow a linear relationship ${ }^{5}$, 


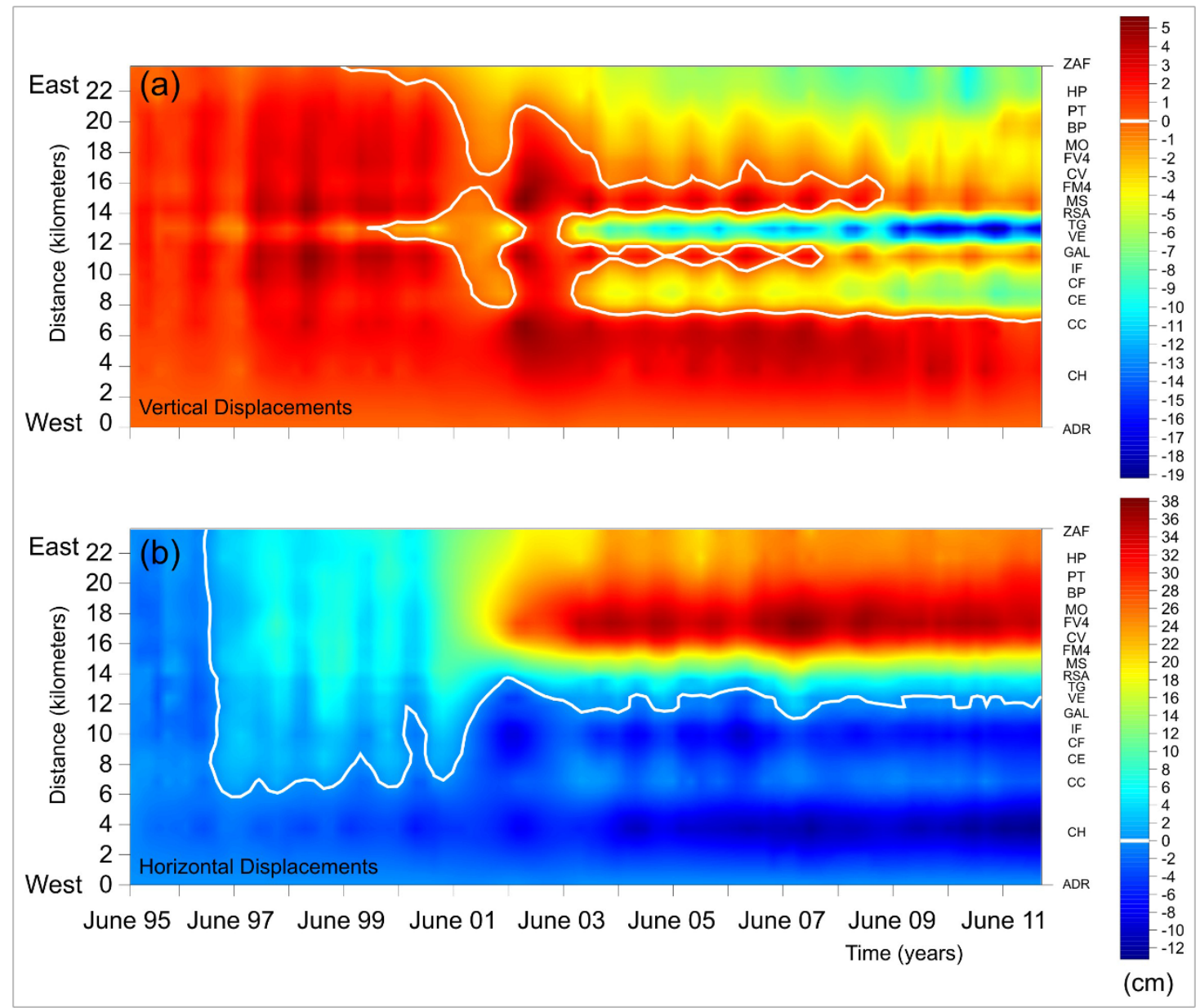

Figure 2 Spatiotemporal vertical (a) and horizontal (b) deformation components along the West-East profile (y axis) from June 1995 to December 2012 ( $\mathrm{x}$ axis) referred to the acquisition in April 1995. The deformation time series are calculated using ENVISAT (1995-2009) and CSK (2009-2011) images as described in the Methods.

which is straightforwardly explained by a pressurized spherical magma chamber embedded in an elastic half-space. The magma is assumed to be fully incompressible and thus, as it is injected or withdrawn, the chamber changes its volume accordingly, deforming the surrounding medium and triggering gravity and elevation changes at the surface ${ }^{5}$. Following this model and assuming typical density of the basaltic magma $\left(2500-2700 \mathrm{~kg} / \mathrm{m}^{3}\right)$, the $\Delta \mathrm{g} / \Delta \mathrm{h}$ ratio, after the free-air correction, ranges between 0.65 and $0.79 \mu \mathrm{Gal} / \mathrm{cm}^{25}$. However, our observations do not confirm this simple model since significant positive gravity changes occur together with slight positive height changes (Fig. 4 ), thus implying that $\Delta \mathrm{g} / \Delta \mathrm{h}$ should show significantly larger values. If the chamber is not spherical and the magma is considered compressible, the $\Delta \mathrm{g} / \Delta \mathrm{h}$ ratio may be higher ${ }^{26}$. According to previous gravity ${ }^{14}$ and geodetic ${ }^{29}$ investigations, Etna's plumbing system has a multifaceted geometry consisting of storage zones at different depths. The intermediate storage zone lies between 2 and $4 \mathrm{~km}$, at a depth where the $\mathrm{SO}_{2}$, the most abundant gas phase at Etna, starts to exsolve. Assuming at this depth magma with average compressibility $^{30}$ of about $0.2 \mathrm{GPa}^{-1}$ and a medium rigidity derived from seismic tomography of $30 \mathrm{GPa}^{29}$, the $\Delta \mathrm{g} / \Delta \mathrm{h}$ ratio for prolate ellipsoids, such as those detected at Etna from geodetic investigations $^{29,8}$, may reach a value of about $13 \mu \mathrm{Gal} / \mathrm{cm}$ (Fig. 5 and Methods). For an ellipsoidal source with aspect ratio of about 1.6, the modeled $\Delta \mathrm{g}$ and $\Delta \mathrm{h}$ values are in general agreement with the data (red dots in Fig. 5) relevant to the recharging phase occurred in 1997 (Fig. 3c, box I), when magma accumulation was the predominant process. The arrival of high compressibility magma may engender larger values of the $\Delta \mathrm{g} / \Delta \mathrm{h}$ ratio, thus implying significant positive gravity variations accompanied by slight positive height changes, as highlighted by our gravity and DInSAR data at Etna volcano. Even if no claim is made that the model strictly applies to the observations, this result shows a significant qualitative agreement with the gravity residuals of about $40 \mu \mathrm{Gal}$ (Fig. $3 \mathrm{c}$ box I; Fig. 4) accompanied by slight height changes of $4 \mathrm{~cm}$ (Fig. $2 \mathrm{a}$ and 4 ) observed during the first recharging phase. This implies the arrival of a fresh magma volume of about $17 \times 10^{6} \mathrm{~m}^{3}$.

South Rift magma intrusions. The second process is linked to the South Rift dynamic along which magma preferably ascends and intrudes at shallow depth triggering eruptions and fissures propagations ${ }^{32}$. It is related to the magma injection and withdrawal in a region recognized to be a preferential pathway of magma rising and a favored intermediate accumulation storage at a depth of 3$5 \mathrm{~km}$ b.s.l. in proximity of the western border of the high-density and high-velocity body detected by gravity prospecting ${ }^{33}$ and seismic tomography ${ }^{34}$. In the South Rift area (from IF to MS gravity stations; Fig. 1) the gravity and deformation patterns changed drastically since 2002, when gravity and height changes were accompanied by a marked horizontal deformation (Fig. 2b). The magmatic intrusions in the South Rift during the 2001 and 20022003 eruptions $^{35,36}$ pushed the volcano flank apart causing a deformation pattern typical of tensile mechanisms with subsidence in the intrusive area and uplift in the zone surrounding the intrusion $^{37}$. In agreement with the deformation pattern, also the 


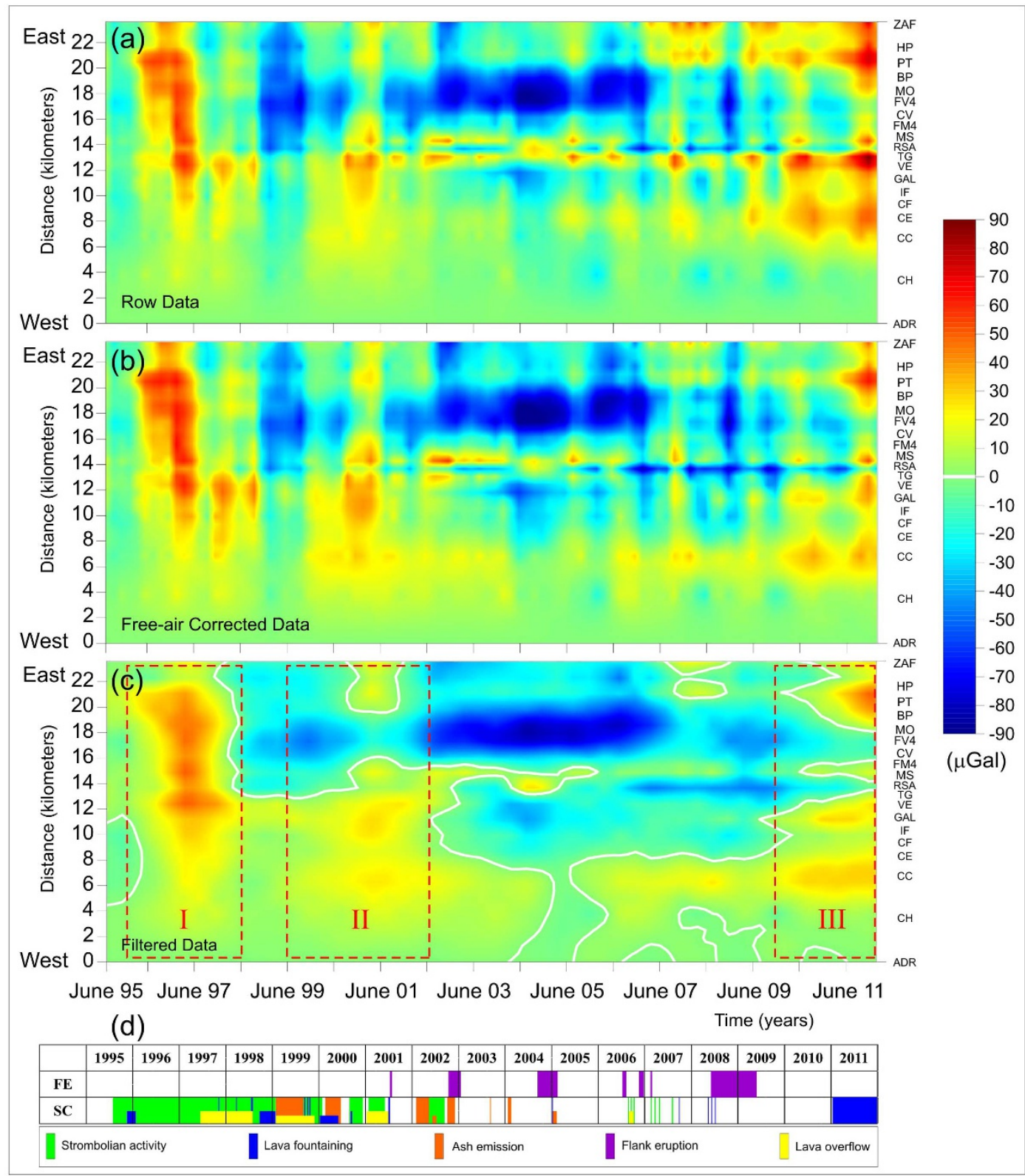

Figure 3 (a) Spatiotemporal gravity variations along the West-East profile (y axis) between June 1995 and December 2011 (x axis). All measurements were referred to the outermost station of the profile (Adrano; ADR). (b) Gravity variations after the correction of the free-air contribution estimated from DInSAR derived height changes. (c) Gravity changes filtered of local noise, short-wavelength spatial and seasonal components using a 2-D wavelet multi-resolution analysis as described in Methods ${ }^{14}$. (d) Etna activity from 1995 to 2011 showing the flank eruptions (FE) and the different eruptive styles at the summit craters (SC).

gravity changes are a fingerprint of the activation of the rift area, displaying across the profile negative variations in the central area bounded by positive variations (Fig. 3). Although changes in the gravity field are generally interpreted only in terms of mass input, numerical models ${ }^{38,37}$ show that for shallow intrusive sources the predominant gravity contribution originates from the displacement of density boundaries. In such a case also the gravity changes display the distinctive tensile pattern that is strongly different from the concentric pattern due to the contribution of mass input alone $^{31,37}$. This tensile pattern persisted over the following years in the South Rift area showing an extensional behavior, consistent with a regional control on the short-term activity of the volcano ${ }^{39,40}$. The negative gravity and height changes in the South Rift area slowed down in late-2009, when the third positive gravity cycle started
(Fig. 2a and 3c, RS-TG-VE stations). The high gradient in the horizontal deformation maps indicates the South Rift area as a main border of the sliding eastern flank ${ }^{17}$, which greatly accelerated after the 2002-2003 eruption.

Eastern flank sliding. The third process is concerned with the predominant eastern flank sliding of Mt Etna, whose dynamic markedly affects the deformation and gravity signals. Clear jumps in the deformation and gravity changes are recognized around active faults crossing the profile, reflecting their relative motions and density discontinuity surfaces. After the 2002-2003 eruption the eastern flank accelerated its seaward sliding with an exceptional horizontal deformation accompanied by vertical changes reaching about $-10 \mathrm{~cm}$ in the easternmost stations ${ }^{17}$. High gradients are 

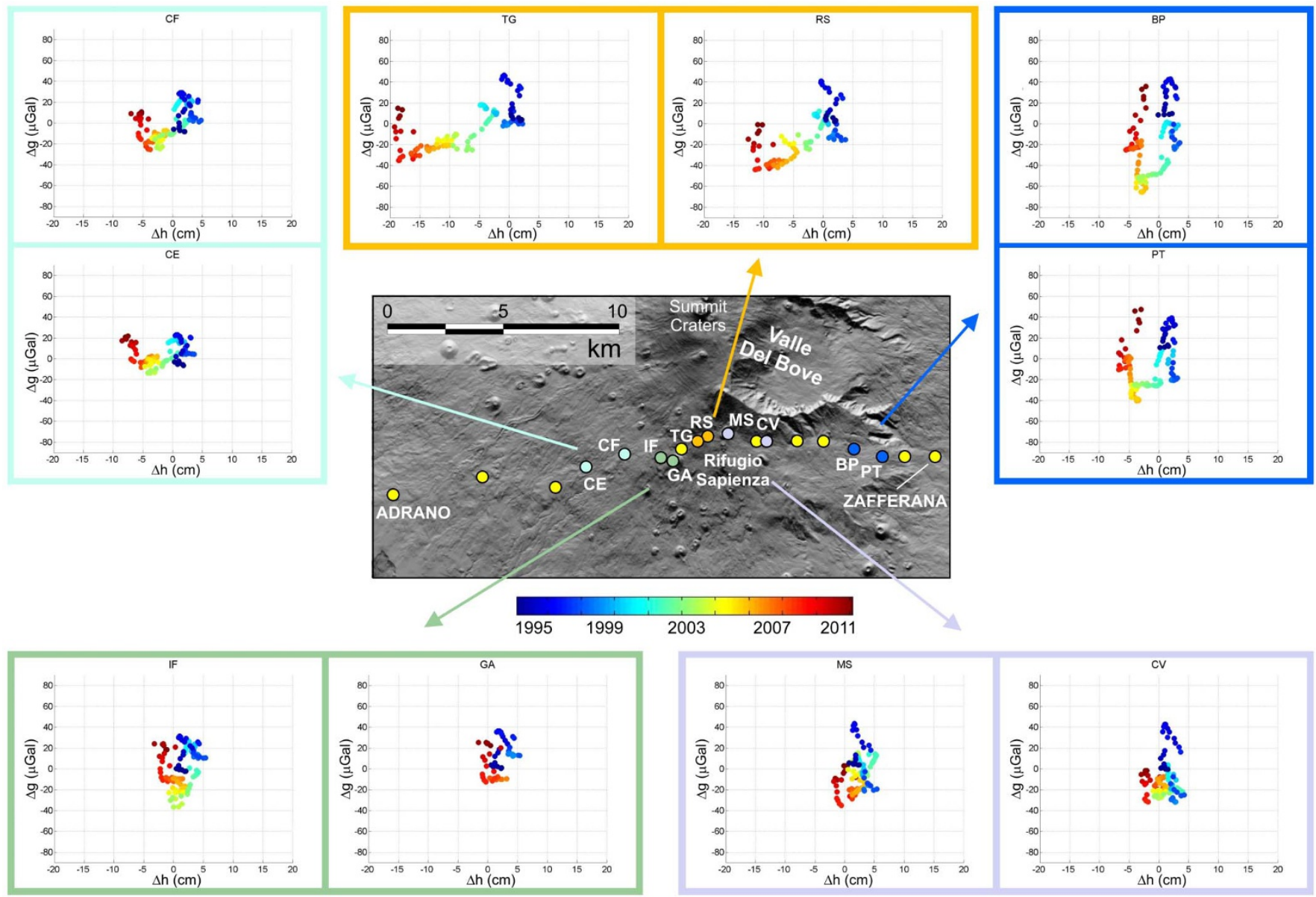

Figure $4 \mid$ Temporal evolution of the gravity-height changes along the profile, visualized using a $\Delta \mathrm{g} / \Delta \mathrm{h}$ diagram ${ }^{5}$. Five patterns localized in distinct sectors of the volcano bounded by main volcano-tectonic structures (Fig. 1) are highlighted.

observed in correspondence to $\mathrm{CV}$ and FV stations, which are located across the border of one of the main sliding rigid blocks (Fig. 1). The horizontal deformation shows a spatial step more than $20 \mathrm{~cm}$ and the gravity changes reverse in sign with a step of about $50 \mu \mathrm{Gal}$. Although with a smaller gradient, another clear discontinuity in the ground deformation and gravity changes is detected in the western flank between the CC and CE stations, which could be attributed to the dynamics of the Ragalna Fault System crossing the profile (Fig. 1), whose creep movement increased after the 2002-2003 eruption. In the eastern flank the strongest decrease in the gravity signal started in the 2002 and is accompanied in space and time by a significant horizontal deformation $(-38 \mathrm{~cm})$, which is about three times larger than that on the western flank. It is worth noting that the gravity decreases faded out as the horizontal deformation ceased. The short wavelengths of the gravity and deformation fields are indicative of shallow and local sources. In this period, this area was also affected by a significant increase in the shallow seismicity (above $5 \mathrm{~km} \mathrm{bs}^{14}$ ) associated with movement along the faults that border the sliding blocks of the unstable eastern flank. Concurrently, one of the most significant $\mathrm{CO}_{2}$ emissions has been recorded here by geochemical prospecting ${ }^{41}$. The intense seismicity could have promoted rock fracture and opening of new voids contributing to density decreases and favoring also gas release $e^{41}$. Density variations related to dilation or contraction of the medium can be reasonably attributed to stress-induced variations in crack porosity $\phi$, which accompany seismic activity. Fault zone porosity is expected to change during co-seismic processes due to the formation of new cracks, changes from ineffective (or isolated) to effective (or connected) porosity (rearrangement of the interconnection chains between existing voids), grain size comminution, and gouge evolution ${ }^{42}$. Assuming average values of basaltic rock density ${ }^{33} \rho_{0}\left(2400-2600 \mathrm{~kg} / \mathrm{m}^{3}\right)$ and reasonable porosity change values $\Delta \phi(0.003-0.006)^{42}$, a negative density change $\Delta \rho=\rho_{0} \Delta \phi$ of about $7-15 \mathrm{~kg} / \mathrm{m}^{3}$ is estimated. Considering such a density decrease within the volume releasing most of the seismic energy after the 2002-2003 eruption, the expected gravity change matches quite well the observed variations along the profile in 2004 (Fig. 6), when the maximum negative change of about $70 \mu \mathrm{Gal}$ is obtained at the gravity stations crossing the eastern region.

\section{Discussion}

Focusing on the spatiotemporal evolution of the vertical and horizontal ground deformation as well as of gravity changes, we shed light on the complex interplay among the main processes controlling the Etna dynamics. In particular, our analysis draws out: (i) unusual large and positive values of the gravity and height change ratio, (ii) a clear influence of the volcano structural setting on both deformation and gravity patterns, and (iii) a complex relationship between volcanic and tectonic processes. Since different mechanisms are involved and overlapped, they likely mask their effects with each other, and make it difficult to find a general and simple relationship between gravity and deformation, as usually occurs in closed volcanic systems ${ }^{5}$.

The analysis of long-period microgravity and DInSAR observations has highlighted, over the last 16 years, a clear signature of the South Rift activity, which shows a tensile pattern typical of extensive mechanisms, the sliding of the eastern flank of the volcanic edifice, 


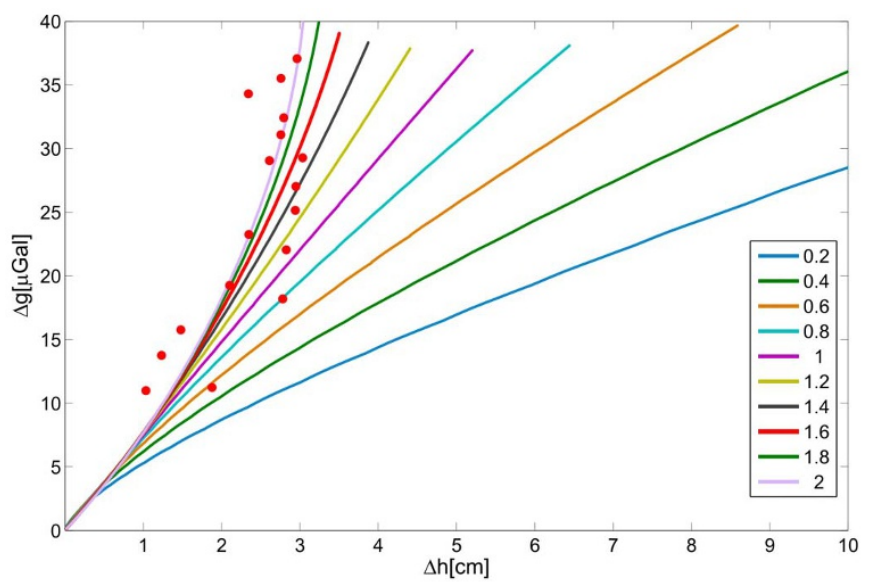

Figure $5 \mid \Delta$ g vs. $\Delta$ h values numerically computed ${ }^{31,53,54}$ for the inflation $(\Delta \mathrm{P}=18 \mathrm{MPa})$ of an ellipsoidal source at a depth of $3 \mathrm{~km}$ with a compressible magma $\chi=0.2 \mathrm{GPa}^{-1}$ embedded in an elastic medium $\mu=30 \mathrm{GPa}$. Ellipsoidal sources at constant volume (equivalent to a sphere with radius of $1 \mathrm{~km}$ ) and with different aspect ratios e between the major and minor axes ranging from 0.2 to 2 (prolate ellipsoid $\mathrm{e}>1$; sphere $\mathrm{e}=1$; oblate ellipsoid $\mathrm{e}<1$ ) are considered (see Methods). The $\Delta \mathrm{g}$ and $\Delta \mathrm{h}$ values for an aspect ratio of about 1.6 is in general agreement with the data (red dots) observed during the 1997 recharging phase (Fig. 3c, box I).

which leads to large horizontal displacements and negative gravity changes attributed to an increase in void and crack growth, and some magma charging phases, which result in moderate uplift and cyclic gravity changes. During the main recharging phases, the ratio between gravity and height variations is indicative of an overall mass increase within the volcano with limited ground deformation (Fig. 4), pointing out a poor interaction between the intermediate storage system (2-4 km depth) and the arrival of fresh magma. This suggests that the magma should be highly compressible and rich in volatiles. In fact, recharging phases have been accompanied with high $\mathrm{SO}_{2}$ flux emissions, preceding paroxysm activity and fire fountaining episodes ${ }^{22}$, in which the gas-rich magma, supplied from intermediate feeding system, propels the lava fountains, following a foam collapse model ${ }^{43,44}$. The cyclic changes in microgravity could arise from the formation of magma batches in the magma storage region resulting from the convective overturn of shallow degassed and denser magma that is replaced periodically by lower density, gas-rich magma from depth. The convective overturn and recycling, at possibly quite low rate, of magma supplying fresh gas-rich melts is a continuous source of volatiles ${ }^{45}$ and is recognized to promote intense eruptive cycles at Etna ${ }^{46}$.

The combined gravity and DInSAR observations provide the signature of recharging phases within the volcano in 1997 and 2001 as well as in 2011, which preceded and accompanied the onset of intense flank eruptions and lava fountaining activity at summit craters (Fig. 3d). Actually, the last magma charging phase preceded by a few months the renewal of the Etna eruptive activity, characterized by 38 episodes of short-lived and high intensity lava fountains from the South-East Crater between 2011 and 2013 (at the time of writing). The quality and quantity of DInSAR data available in terms of spatial and temporal resolution allowed not only capture of the deformation pattern but also interpretation of microgravity changes to detect possible magma rising in months to years before the onset of a new Etna eruption. Ultimately, using complementary gravity and DInSAR data will help move us toward a realistic forecasting of eruptions, which comes from a better understanding of processes happening within a volcano edifice.

\section{Methods}

DInSAR measurements. Along the West-East profile we generated a first time series obtained from a data set composed of 132 descending and 155 ascending orbit SAR images, acquired by ERS/ENVISAT satellites (from 1995 to 2009); a second time series was generated by using 119 descending and 121 ascending images acquired by COSMO-SkyMed (CSK) satellites (from 2009 to 2011). In the 2000-2003 period, DInSAR data became discontinuous because of the unavailability of two out of three satellites (ERS1 mission terminated in 2000, ENVISAT began in March 2002) while a gyroscope failure on the remaining satellite (ERS2) occurred in January 2001 and was not recovered until late 2001 when the satellite attitude was again put within the specifications ${ }^{47}$. The satellite data were processed using the Small Baseline Subset (SBAS) algorithm ${ }^{48}$, which allows us to detect surface displacements and analyze their temporal evolution by generating deformation time series projected along the radar line of sight (LOS). The LOS ascending and descending deformation time series were subsequently combined to resolve for vertical and horizontal (east-west) displacements. Since for this site the data were acquired quite regularly from both orbits, each ascending acquisition could be combined to a corresponding descending one acquired a few days later ${ }^{17}$. The obtained vertical and horizontal time series relevant to the 1995-2009 and 2009-2011 time intervals were finally connected by using a continuity criterion, thanks to the higher temporal resolution of CSK data.

Among the obtained deformation time series, we selected those pertinent to coherent SAR pixels that were the closest to each gravity benchmark (the distance between the SAR pixels and the corresponding gravity benchmark ranges from 21 to $700 \mathrm{~m}$ for the ERS/ENVISAT series and from 8 to $300 \mathrm{~m}$ for the higher resolution CSK data, Fig. 1). Figure 2 shows the horizontal and vertical deformation measured in the West-East profile stations between June 1995 and December 2011. The SBAS time series accuracy is assumed to be less than $1 \mathrm{~cm}$, in accordance with previous studies ${ }^{49}$. The vertical deformation ranges between $-20 \mathrm{~cm}$ and $6 \mathrm{~cm}$ associated with a horizontal deformation from $-13 \mathrm{~cm}$ to $38 \mathrm{~cm}$ (eastward motion is represented by positive values) over the whole considered period. The most significant displacements are detected starting from 2002 and affect the middle and the eastern part of the profile. In particular, the largest height displacement reached about $-20 \mathrm{~cm}$ around 2008 in proximity to the TG gravity station, in the middle part of the profile; on the other hand, the maximum amplitude in horizontal displacements $(38 \mathrm{~cm})$ is located in correspondence to the $\mathrm{CV}, \mathrm{FV}$ and MO gravity stations on the eastern side of the profile.

Gravity measurements. Microgravity measurements were conducted along the West-East profile by the "step method"14,50, thus each pair of adjacent stations are connected at least three times in order to monitor continuously instrumental performance. Since its installation (summer of 1994), 121 surveys were carried out quasi-monthly until December 2011 using the Scintrex CG-3M gravimeter (serial \# 9310234), which is periodically calibrated along the Catania - Etna absolutecalibration-line ${ }^{15}$

All measurements were then referred to the westernmost station of the profile (ADR, Fig. 1), since it is the least likely station to be affected by temporal gravity changes $^{14}$. The uncertainty in gravity measurements, collected with the Scintrex CG$3 \mathrm{M}$ gravimeter, ranges, on average, between \pm 7 and $\pm 11 \mu \mathrm{Gal}$ at the 95 percent confidence interval ${ }^{14}$. Fig. 3a shows the gravity variations measured in the West-East profile stations from June 1995 to December 2011. To interpret the gravity changes over time, it is necessary to reduce the gravity data for the free-air effect, seasonal variations and several high-frequency disturbances ${ }^{51,14}$. The observed gravity data were firstly corrected for elevation changes using the DInSAR derived vertical deformation (Fig. 2a) and the theoretical vertical gravity gradient $(-3.086 \mu \mathrm{Gal} / \mathrm{cm}$ ). Vertical uplifts, evaluated by DInSAR time series during the entire period, show large variations able to induce significant gravity changes. Moreover, the high gradient along the profile in the vertical deformation addresses that free-air contributions must be estimated at each station to perform accurate corrections. Thanks to the high spatial resolution and the good accuracy, DInSAR derived height changes could fill the lack of GPS measurements at each gravity station. In Fig. $3 \mathrm{~b}$ the corrected free-air gravity changes are shown. Free-air corrections do not significantly modify the spatiotemporal gravity map until 2007 (Figs. 3a-b). Afterwards, important free-air contributions are estimated. Particularly, positive gravity changes recorded since 2007 in the easternmost stations fade out after the correction, while in the central and western parts the positive changes are reduced and the negative ones are enhanced as a result of the negative height changes recorded in this area after 2002-2003 (Fig. 2a). The free-air contribution is remarkable in the middle sector of the profile at the TG gravity station in proximity of the South Rift, where a maximum value of about $60 \mu \mathrm{Gal}$ was estimated in correspondence to the largest height changes $(-20 \mathrm{~cm}$, Fig. 2a). The free-air corrected gravity map was then filtered using a 2-D wavelet multi-resolution analysis ${ }^{14}$ to reduce the high frequency variations, related to human and environmental disturbances, and the seasonal fluctuations, mainly due to watertable fluctuations, and to highlight the useful signals (i.e. the volcano-related one). Figure $3 \mathrm{c}$ shows the residual spatiotemporal gravity map, where both significant positive and negative gravity changes are observed in the analyzed period.

Gravity-height changes. The ratio between gravity and elevation changes for a spherical chamber charged with incompressible magma, after the free-air correction, is proportional to the magma density $\rho_{\mathrm{m}}$ as $\frac{\Delta g}{\Delta h}=\frac{4}{3} \pi G \rho_{m}$, where $\mathrm{G}$ is the universal gravitational constant ${ }^{52}$. If the magma is considered compressible, after some algebra following Bonafede and Ferrari ${ }^{26}$, the $\Delta \mathrm{g} / \Delta \mathrm{h}$ ratio is modified as 

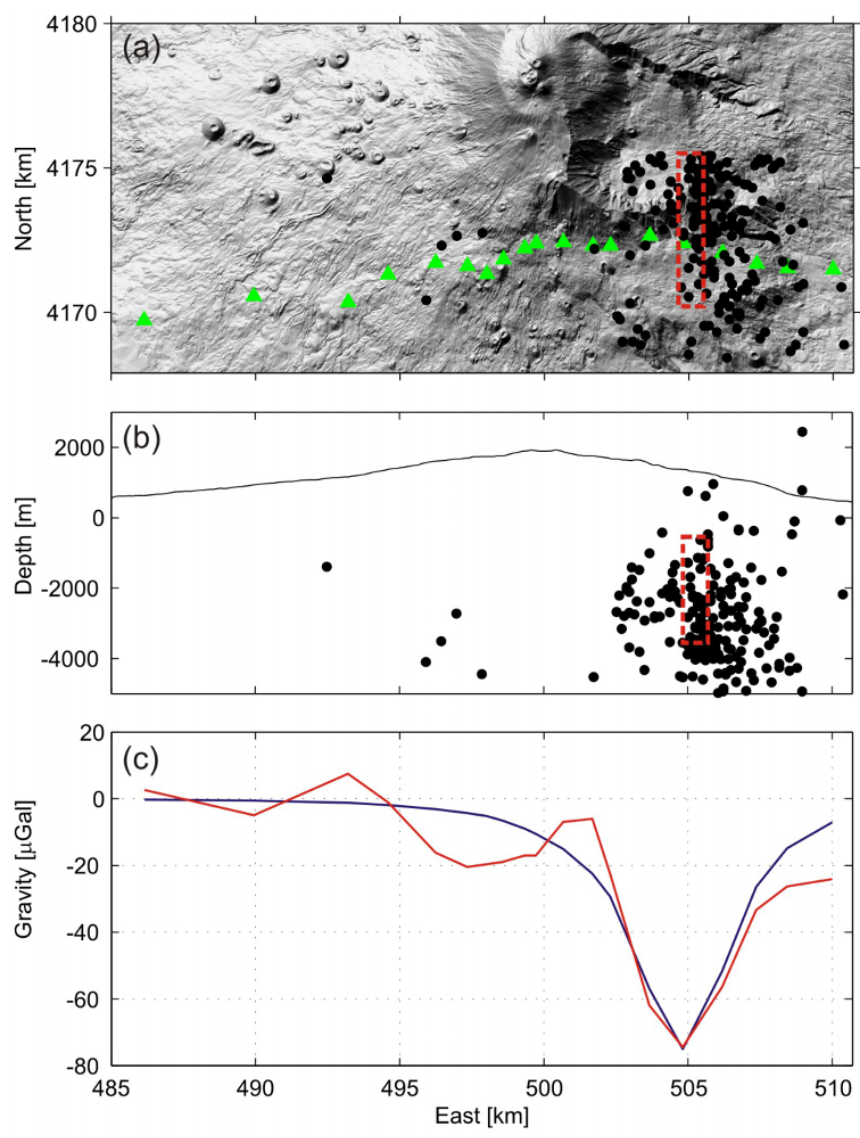

Figure 6 Gravity variations expected by stress induced porosity changes. The gravity source is modeled by a density decrease of $10 \mathrm{~kg} / \mathrm{m}^{3}$ within a rectangular prism ${ }^{55}$ (width $=1 \mathrm{~km}$, height $=3 \mathrm{~km}$, length $=5 \mathrm{~km}$; red dashed rectangle), covering the volume that released most of the seismic energy after the 2002-2003 eruption. (a) Seismic event distributions from 2003 to 2005 (black circles) in the area covered by the gravity stations (green triangles). (b) West-East section showing the distribution with depth of the seismicity. (c) Computed (blue line) and observed (red line) gravity changes along the profile. Geographical coordinates are expressed in UTM projection, zone $33 \mathrm{~N}$.

$\frac{\Delta g}{\Delta h}=\frac{4}{3} \pi G \rho_{m}\left(1+\frac{4}{3} \mu \chi\right)$, where $\mu$ is the rigidity of the surrounding rock and $\chi$ the magma compressibility controlled by magma chamber conditions (i.e., pressure, gas volume fraction, phenocryst content, and temperature). Magma compressibility is very small for a gas-free magma $\left(0.04-0.2 \mathrm{GPa}^{-1}\right)^{27}$ but relatively large if volatiles exsolve, reaching, for basaltic magma, $10 \mathrm{GPa}^{-1}$ depending on depth ${ }^{28}$, or even more for felsic magma. Considering average values of medium rigidity $(0.1-30 \mathrm{GPa})$, the term $\left(1+\frac{4}{3} \mu \chi\right)$ may be relevant ${ }^{28}$ and range between 1.05 and 9 , thus giving a maximum ratio of $6.28 \mu \mathrm{Gal} / \mathrm{cm}$. The $\Delta \mathrm{g} / \Delta \mathrm{h}$ ratio is also affected by the source geometry. While for gravity changes the geometry effect is negligible, for height changes it can strongly affect the solution. At a constant volume, the pressurization of a prolate ellipsoid engenders lower height changes with respect to a spherical source as the aspect ratio increases ${ }^{31}$. The expected $\Delta \mathrm{g} / \Delta \mathrm{h}$ ratio for ellipsoidal sources at a depth of $3 \mathrm{~km}$ with different ellipse aspect ratios from 0.2 to 2 were numerically computed ${ }^{31,53,54}$, considering also the effect of magma compressibility. The $\Delta \mathrm{g} / \Delta \mathrm{h}$ ratio is larger for prolate ellipsoids and may reach $13 \mu \mathrm{Gal} / \mathrm{cm}$ (Fig. 5).

1. Carbone, D., Budetta, G. \& Greco, F. Bulk processes prior to the 2001 Mount Etna eruption, highlighted through microgravity studies. J. Geophys. Res. 108, B12, 2556, DOI:10.1029/2003JB002542 (2003).

2. Currenti, G., Napoli, R. \& Del Negro, C. Toward a realistic deformation model of the 2008 magmatic intrusion at Etna from combined DInSAR and GPS observations. Earth Planet. Sc. Lett. 312, 22-27, DOI: 10.1016/j.epsl.2011.09.058 (2011).
3. Battaglia, M., Troise, C., Obrizzo, F., Pingue, F. \& De Natale, G. Evidence for fluid migration as the source of deformation at Campi Flegrei caldera (Italy). Geophys. Res. Lett. 33, L01307, DOI:10.1029/2005GL024904 (2006).

4. Gottsmann, J., Rymer, H. \& Berrino, G. Caldera unrest at the Campi Flegrei: A critical evaluation of source parameters from geodetic data inversion. J. Volcanol. Geotherm. Res. 150, 132-145 (2006).

5. Williams-Jones, G. \& Rymer, H. Detecting volcanic eruption precursors: a new method using gravity and deformation measurements. J. Volcanol. Geotherm. Res. $113,379-389$ (2002).

6. Carbone, D., Budetta, G. \& Greco, F. Possible mechanisms of magma redistribution under Mt Etna during the 1994-1999 period detected through microgravity measurements. Geophys. J. Int. 153, 187-200 (2003).

7. Gottsmann, J. et al. New evidence for the reactivation of Teide volcano. Geophys. Res. Lett. 33, DOI:10.1029/2006GL027523 (2006).

8. Bonaccorso, A. et al. Magma storage, eruptive activity and flank instability: Inferences from ground deformation and gravity changes during the 1993-2000 recharging of Mt. Etna volcano. J. Volcanol. Geoth. Res. 200, 245-254 (2011).

9. Gabriel, A. K., Goldstein, R. M. \& Zebker, H. A. Mapping small elevation changes over large areas: Differential radar interferometry. J. Geophys. Res. 94, 9183-9191 (1989).

10. Massonnet, D. et al. The displacement field of the Landers earthquake mapped by radar interferometry. Nature 364, 138-142 (1993).

11. Sansosti, E., Casu, F., Manzo, M. \& Lanari, R. Space-borne radar interferometry techniques for the generation of deformation time series: an advanced tool for Earth's surface displacement analysis. Geophys. Res. Lett. 37, L20305, DOI:10.1029/2010GL044379 (2010).

12. Solaro, G. et al. SBAS-DInSAR time series in the last eighteen years at Mt. Etna volcano (Italy). 2011 IEEE International Geoscience and Remote Sensing Symposium (IGARSS) 3891-3894, DOI: 10.1109/IGARSS.2011.6050081 (2011).

13. Solaro, G. et al. E. Anatomy of an unstable volcano from InSAR: Multiple processes affecting flank instability at Mt. Etna, 1994-2008. J. Geophys. Res. 115, B10405, DOI:10.1029/2009JB000820 (2010).

14. Greco, F. et al. Spatiotemporal gravity variations to look deep into the southern flank of Etna volcano. J. Geophys. Res. 115, B11411, DOI:10.1029/2009JB006835 (2010).

15. Greco, F. et al. Combining relative and absolute gravity measurements to enhance volcano monitoring at Mt Etna (Italy). Bull Volcanol. 74, 1745-1756, DOI: 10.1007/s00445-012-0630-0 (2012).

16. Ruch, J. et al. Detachment depth revealed by rollover deformation: An integrated approach at Mount Etna. Geophys. Res. Lett. 37, L16304, DOI:10.1029/ 2010GL044131 (2010).

17. Ruch, J. et al. How do rift zones relate to volcano flank instability? Evidence from collapsing rifts at Etna. Geophys. Res. Lett. 39, L20311, DOI:10.1029/ 2012GL053683 (2012).

18. Acocella, V., Behncke, B., Neri, M. \& D'Amico, S. Link between major flank slip and eruptions at Mt. Etna (Italy). Geoph. Res. Lett. 30, 24, 2286, DOI:10.1029/ 2003GL018642 (2003).

19. Borgia, A., Ferrari, L. \& Pasquarè, G. Importance of gravitational spreading in the tectonic and volcanic evolution of Mount Etna. Nature 357, 231-235 (1992).

20. Rust, D. \& Neri, M. The boundaries of large-scale collapse on the flanks of Mount Etna, Sicily in Volcano Instability on the Earth and Other Planets (eds McGuire, W. J., Jones, A. P. \& Neuberg, J.) 193-208 (Geol. Soc. Lond. Spec. Pub., 110 1996).

21. Bonforte, A., Guglielmino, F., Coltelli, M., Ferretti, A. \& Puglisi, G. Structural assessment of Mt. Etna volcano from Permanent Scatterers analysis. Geochem. Geophys. Geosyst. 12, Q02002, DOI: 10.1029/2010GC003213 (2011).

22. Allard, P., Behncke, B., D’Amico, S., Neri, M. \& Gambino, S. Mount Etna 1993-2005: Anatomy of an evolving eruptive cycle. Earth Sci. Rev. 78, 85-114 (2006).

23. Lundgren, P. et al. Coupled magma chamber inflation and sector collapse slip observed with synthetic aperture radar interferometry on Mt. Etna volcano. J. Geophys. Res. 108, 2247, DOI:10.1029/2001JB000657 (2003).

24. Lanari, R., Lundgren, P. \& Sansosti, E. Dynamic deformation of Etna volcano observed by satellite radar interferometry. Geophys. Res. Lett. 25, 10, 1541-1544, DOI: 10.1029/98GL00642 (1998).

25. Carbone, D., Currenti, G. \& Del Negro, C. Elastic model for the gravity and elevation changes before the 2001 eruption of Etna volcano. Bull. Volcanol. 69, 553-562, DOI: 10.1007/s00445-006-0090-5 (2007).

26. Bonafede, M. \& Ferrari, C. Analytical models of deformation and residual gravity changes due to a Mogi source in a viscoelastic medium. Tectonophysics 471, 4-13 (2009).

27. Spera, F. J. Physical properties of magmas in Encyclopedia of Volcanoes (ed Sigurdsson, H.) 171-190 (Elsevier, New York, 2000).

28. Rivalta, E. \& Segall, P. Magma compressibility and the missing source for some dike intrusions. Geophys. Res. Lett. 35, L04306, DOI:10.1029/2007GL032521 (2008).

29. Bonforte, A., Bonaccorso, A., Guglielmino, F., Palano, M. \& Puglisi, G. Feeding system and magma storage beneath Mt. Etna as revealed by recent inflation/ deflation cycles. J. Geophys. Res. 113, B05406, DOI:10.1029/2007JB005334 (2008).

30. Huppert, H. E. \& Woods, A. W. The role of volatiles in magma chamber dynamics. Nature 420, 493-495 (2002). 
31. Currenti, G., Del Negro, C. \& Ganci, G. Modelling of ground deformation and gravity fields using finite element method: An application to Etna volcano. Geoph. J. Int. 169, DOI: 10.111/j.1365-246X.2007.03380.x. (2007).

32. Cappello, A. et al. Spatial vent opening probability map of Mt Etna volcano (Sicily, Italy). Bull. Volcanol. 74, 2083-2094, DOI:10.1007/s00445-012-0647-4 (2012).

33. Schiavone, D. \& Loddo, M. 3-D density model of Mt. Etna Volcano (Southern Italy). J. Volcanol. Geoth. Res. 164, 161-175 (2007).

34. Patané, D., De Gori, P., Chiarabba, C. \& Bonaccorso, A. Magma ascent and the pressurization of Mount Etna's volcanic system. Science 299, 2061-2063, DOI: 10.1126/science.1080653 (2003).

35. Bonaccorso, A., Currenti, G., Del Negro, C. \& Boschi, E. Dike deflection modelling for inferring magma pressure and withdrawal, with application to Etna 2001 case. Earth Planet. Sc. Lett. 293, 121-129, DOI:10.1016/j.epsl.2010.02.030 (2010).

36. Neri, M. et al. Contrasting triggering mechanisms of the 2001 and 2002-2003 eruptions of Mount Etna (Italy). J. Volcanol. Geotherm. Res. 144, 235-255 (2005).

37. Currenti, G., Napoli, R., Di Stefano, A., Greco, F. \& Del Negro, C. 3D integrated geophysical modeling for the 2008 magma intrusion at Etna: Constraints on rheology and dike overpressure. Phys. Earth Planet. Int. 185, 44-52, DOI:10.1016/ j.pepi.2011.01.002 (2011).

38. Okubo, S. Gravity and Potential Changes due to Shear and Tensile Faults in a HalfSpace. J. Geoph. Res. 97(B5), 7137-7144 (1992).

39. Lanzafame, G., Leonardi, A., Neri, M. \& Rust, D. Late overthrust of the AppenineMaghrebian Chain at the NE periphery of Mt. Etna, Italy. C.R. Acad. Sc. Paris 324(IIa), 325-332 (1997)

40. Monaco, C. et al. Tectonic control on the eruptive dynamics at Mt. Etna volcano (eastern Sicily) during the 2001 and 2002-2003 eruption. J. Volcanol. Geotherm. Res. 144, 221-233 (2005).

41. Federico, C., Camarda, M., De Gregorio, S. \& Gurrieri, S. Long-term record of $\mathrm{CO} 2$ degassing along Mt. Etna's flanks and its relationship with magma dynamics and eastern flank instability. Geochem. Geophys. Geosyst. 12, Q10002, DOI: 10.1029/2011GC003601 (2011)

42. Bizzarri, A. Effects of permeability and porosity evolution on simulated earthquakes. J. Struct. Geol. 38, 243-253, DOI:10.1016/j.jsg.2011.07.009 (2012).

43. Jaupart, C. \& Vergniolle, S. Laboratory models of Hawaiian and Strombolian eruptions. Nature 331, 58-60 (1988).

44. Bonaccorso, A. et al. From source to surface: Dynamics of Etna's lava fountains investigated by continuous strain, magnetic, ground and satellite thermal data. Bull. Volcanol. 75, 690, DOI: 10.1007/s00445-013-0690-9 (2013).

45. Allard, P. Endogenous magma degassing and storage at Mount Etna. Geophys. Res. Lett. 24, 2219-2222 (1997).

46. Corsaro, R. A. \& Pompilio, M. Buoyancy-controlled eruption of magmas at Mt Etna. Terra Nova 16, 16-22 (2004).

47. Miranda, N., Rosich, B., Santella, C. \& Grion, M. Review of the impact of ERS-2 piloting modes on the sar doppler stability. Proc. of FRINGE 2003 Workshop, Frascati, Italy, 1-5 December 2003 (2004)

48. Berardino, P., Fornaro, G., Lanari, R. \& Sansosti, E. A new algorithm for surface deformation monitoring based on small baseline differential SAR interferograms.
IEEE Trans. Geosci. Remote Sensing 40, 2375-2383, DOI: 10.1109/ TGRS.2002.803792 (2002).

49. Casu, F., Manzo, M. \& Lanari, R. A quantitative assessment of the SBAS algorithm performance for surface deformation retrieval from DInSAR data. Remote Sens. Environ. 102, 3-4, pp. 195-210, DOI: 10.1016/j.rse.2006.01.023 (2006).

50. Pistorio, A. et al. High precision gravity measurements using absolute and relative gravimeters at Mount Etna (Sicily, Italy). Annals Geophys. 54, 5, DOI:10.4401/ag534 (2011).

51. Battaglia, M. \& Hill, D. P. Analytical modeling of gravity changes and crustal deformation at volcanoes: The Long Valley caldera, California, case study. Tectonophysics 471, 45-57, DOI:10.1016/j.tecto.2008.09.040 (2009).

52. Hagiwara, Y. The Mogi model as a possible cause of the crustal uplift in the eastern part of Izu Peninsula and related gravity change. Bull. Earthq. Res. Inst., Tokyo Univ. 52, 301-309 (1977)

53. Amoruso, A. \& Crescentini, L. Shape and volume change of pressurized ellipsoidal cavities from deformation and seismic data. J. Geophys. Res. 114, B02210, DOI:10.1029/2008JB005946 (2009).

54. Currenti, G., Del Negro, C. \& Ganci, G. Finite element modeling of ground deformation and gravity field at Mt. Etna. Annals Geophys. 51, 1, 105-119 (2008).

55. Blakely, R. J. Potential Theory in Gravity and Magnetic Applications (Cambridge Univ. Press, New York, 1995)

\section{Acknowledgments}

This work has been partially supported by Italian Space Agency (ASI) within the SAR4Volcanoes project, agreement $\mathrm{n}$. I/034/11/0. The authors are also indebted to the staff of INGV-Catania, who ensured the regular working of the gravity network of Etna. The seismic data were extracted from the databases of the VOLUME project (European Commission FP6-2004-Global-3, http://ctwall.ct.ingv.it/volume/index.asp).

\section{Author contributions}

C.D.N., G.C. and E.S. coordinated the writing of the paper and the research it is based on; DInSAR processing and analysis were undertaken by G.S., A.P., S.P. and F.C.; gravity measurements were carried out and analyzed by F.G. with the contribution of R.N.; G.C. assisted in data processing and performed numerical modeling.

\section{Additional information}

Competing financial interests: The authors declare no competing financial interests.

How to cite this article: Del Negro, C. et al. Capturing the fingerprint of Etna volcano activity in gravity and satellite radar data. Sci. Rep. 3, 3089; DOI:10.1038/srep03089 (2013)

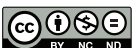

This work is licensed under a Creative Commons AttributionNonCommercial-NoDerivs 3.0 Unported license. To view a copy of this license, visit http://creativecommons.org/licenses/by-nc-nd/3.0 